\title{
THE IMPACT OF FUSARIUM GRAMINEARUM INFECTION ON DIFFERENT PLANT SEEDS
}

\author{
Neringa Rasiukeviciute, Jurgita Kelpsiene \\ Lithuanian Research Centre for Agriculture and Forestry, Lithuania \\ n.rasiukeviciute@1sdi.lt
}

\begin{abstract}
Healthy seeds are essential for the optimal plant population and yield, but seed-borne pathogens, such as Fusarium spp., may reduce seed germination, quality and cause damping-off of the seedlings. Fusarium graminearum is a dominant pathogen of cereal crops and can cause significant losses of grain yield and quality. It is important to evaluate the role of alternative inoculum source in crop rotation. The aim of this study was to assess the impact of $F$. graminearum infection on different plant seed germination and seed infestation. The research was conducted at the Institute of Agriculture, Lithuanian Research Centre for Agriculture and Forestry, in 2017. Visually healthy seeds of bean (Vicia faba L.), pea (Pisum sativum L.), lupine (Lupinus angustifolius L.), soybean (Glycine max. (L.) Merr.), lucerne (Medicago sativa L.), white (Trifolium repens L.) and red (Trifolium pratense L.) clover were inoculated with $10 \mathrm{~mL}$ of $F$. graminearum suspension, adjusted to $1 \times 10^{6}$ conidia per $\mathrm{mL}$. Seed infection was counted 2 and 6 days after inoculation (DAI), seed germination energy and reduction rate - after 3 DAI and germination index - 6 DAI. Results showed that all inoculated seeds were covered with typical to $F$. graminearum red-purple mycelium. The results of inoculated seeds with $F$. graminearum showed red-purple mycelium growth on the seeds (infection from 21.25 up to $100 \%)$. The results showed that germination energy decreased on pea $(2.56 \%)$ and lupine $(7.79 \%)$ seeds. Our results suggest that various plant seeds differently react to $F$. graminearum infection. The highest infection of $F$. graminearum was obtained on pea, lupine seeds and the least on red clover.
\end{abstract}

Key words: germination, infection, inoculation.

\section{Introduction}

One of the important inputs for crop production is seeds. Healthy seeds are essential for the optimal plant population and yield. Numerous diseases are associated with seeds. Diseased seed often looks discoloured or shrunken, but there may be exceptions. Conventionally, the cereal seeds are treated with fungicides regardless of seed health and expected disease. Some of the diseases are controlled by sorting the seeds by size and seed density during seed cleaning. Seed-borne disease cause at least $10 \%$ of yield losses. The seed-borne pathogens may reduce seed germination, quality and cause damping-off of the seedlings. Seed-borne diseases are associated with a lack of adequate amount of fungicides to control diseases. The understanding of the seed-borne pathogens may be helpful in reducing losses and improving yields (Borgen, 2005; Leslie \& Summerell, 2006; Cram \& Fraedrich, 2010; Farrag \& Moharam 2012; Yang et al., 2013; Purahong et al., 2014).

Fusarium spp. associated pathogens are important to cereal crops causing significant losses of grain yield and quality. Fusarium spp. infected seeds could look healthy but has fungus inside. Fusarium graminearum Schw. cause Fusarium head blight (FHB) of small grain cereals. The mycotoxin contamination and yield reduction make FHB primarily cereal disease. There are several Fusarium species which cause FHB, but $F$. graminearum is the most frequent species in many cereal-growing regions. The primary host plants $F$. graminearum are wheat (Triticum aestivum L.), barley (Hordeum vulgare L.), rice (Oryza sativa $\mathrm{L}$.), oats (Avena sativa $\mathrm{L}$.), triticale ( $\mathrm{x}$
Triticosecale Wittm.), rye (Secale cereale L.), maize (Zea mays L.). There are several reports stating that this fungus causes symptoms on some nongraminaceous crops. Fusarium spp. also is associated with seed-borne diseases. The infected seed inoculum is a source of Fusarium foot rot (Ali et al., 2005; Leslie \& Summerell, 2006; Broders et al., 2007; Burlakoti et al., 2008; Xu et al., 2008; Cram \& Fraedrich, 2010; Yang et al., 2013; Mourelos et al., 2014; Purahong et al., 2014). Seed-borne pathogens can be present on seeds without evident signs. Many factors are related to seed-borne diseases (Cram \& Fraedrich, 2010). The detection of seed-borne diseases is an important aspect of its management. Therefore, it is important to use healthy seed material to have optimal and good quality yield. The increased spread of $F$. graminearum was recently noticed in Lithuanian cereals (Suproniene et al., 2015). That could lead to an increased inoculum of $F$. graminearum in the primary source of infection - host plant residues remaining in the soil. Therefore, it is important to know the possible influence of this fungus on the other crop rotation plants, which could be susceptible to the pathogen. The aim of this study was to assess the impact of Fusarium graminearum infection on different plant seed germination and seed infestation.

\section{Materials and Methods}

The research was carried out at the Institute of Agriculture, Lithuanian Research Centre for Agriculture and Forestry, in Central Lithuania (54'53'32.4 N $23^{\circ} 50^{\prime} 16.2$ E) in 2017. The infection of Fusarium graminearum was assessed on different legume seeds: 
bean (Vicia faba L.), pea (Pisum sativum L.), lupine (Lupinus angustifolius L.), soybean (Glycine max. (L.) Merr.), lucerne (Medicago sativa L.), white (Trifolium repens L.) and red (Trifolium pratense L.) clover.

F. graminearum 4vkv4 was isolated from spring wheat (FHB-infected head) in 2016. The isolate was identified morphologically as $F$. graminearum and verified by species-specific PCR, using the protocol and primer pairs suggested by Demeke et al. (2005). Before the experiments, $F$. graminearum isolates were cultured on Potato dextrose agar (PDA) at $25{ }^{\circ} \mathrm{C}$ for 7 days in the dark. Then isolate was transferred onto Spezieller Nährstoffarmer Agar (SNA) (Nirenberg, 1976), incubated at $25 \pm 2{ }^{\circ} \mathrm{C}$ for 14 days, until the formation of a macroconidial mass.

The seed inoculation procedure was made based on a modified Petri-dish test suggested by Purahong et al. (2012) with some modifications. Each tested plant seed was inoculated with $F$. graminearum $4 \mathrm{vkv} 4$ isolate, in four replicates. One replicate consisted of 20 visually healthy seeds, inoculated with $10 \mathrm{ml}$ of $F$. graminearum suspension. The $F$. graminearum macroconidial concentration was adjusted to $1 \times 10^{6}$ conidia per $\mathrm{ml}$. All tested plant seeds before inoculation were surface sterilised in $2 \%$ sodium hypochlorite for $3 \mathrm{~min}$ and then rinsed 6 times with sterile distilled water. The control treatment was soaked only in sterile distilled water. Various plant seeds were laid out in $15 \mathrm{~cm}$ diameter glass Petri plates with sterile doublelayer filter paper. To increase relative humidity, each replicate of Petri was put in a clear polyethylene bag and then incubated at $22^{\circ} \mathrm{C}$ in the dark.
The infection of different plant seeds was counted 2 and 6 days after inoculation (DAI), germination energy after 3 DAI and germination index 6 DAI. Seed germination was evaluated according to Aswathaiah et al. (1993). Germination reduction rate was calculated after 3 DAI according to Purahong et al. (2012). Germination index was calculated after 6 DAI according to Opio \& Photchanachai (2016). Germination index was calculated after the seeds with normal germination were classified and recorded. The seeds were considered germinated when they had root and shoot. $F$. graminearum infected plant seeds were identified visually and/or by mycelium completely covering the seeds (Figure 1). The experiment was repeated. After the experiment, re-isolation of mycelium was done and morphologically identified.

Data analysis was performed using ANOVA, from the package SELEKCIJA. Duncan's multiple range test was used to determine the significant difference between different treatments $(\mathrm{P}<0.05)$ (Raudonius, 2017).

\section{Results and Discussion}

This study was carried out to evaluate the impact of $F$. graminearum on various plant seed germinations and infestations. The data was obtained by in vitro tests. In general, F. graminearum is an important pathogen causing Fusarium head blight (FHB) of small grain cereals. However, it causes diseases on other plants (Purahong et al., 2012; Barros et al., 2014; Suproniene et al., 2016). Broders et al. (2007)

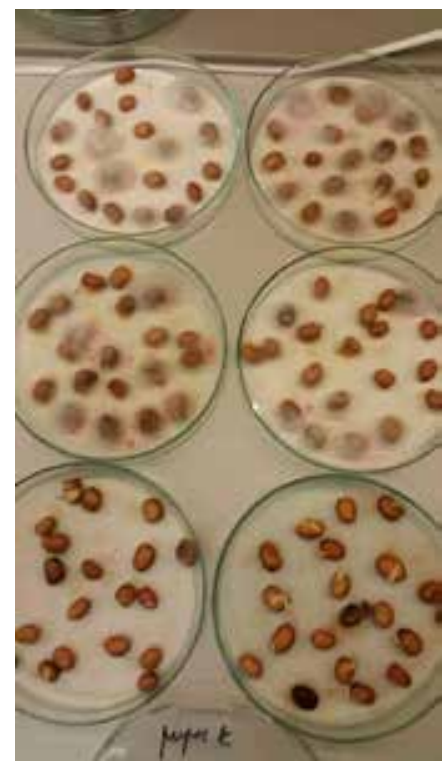

Bean

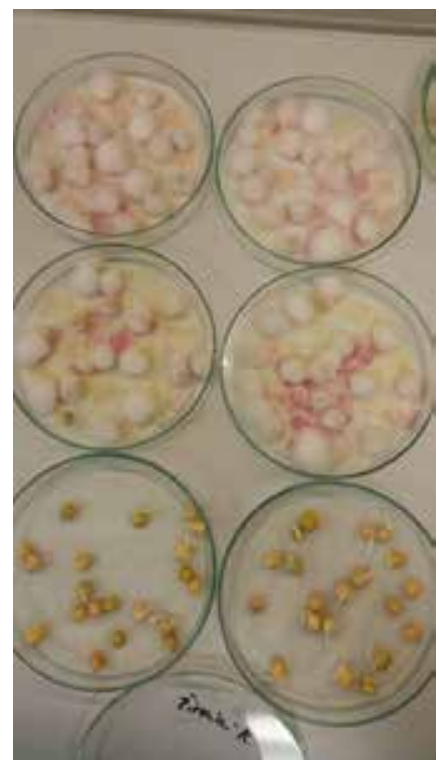

Pea

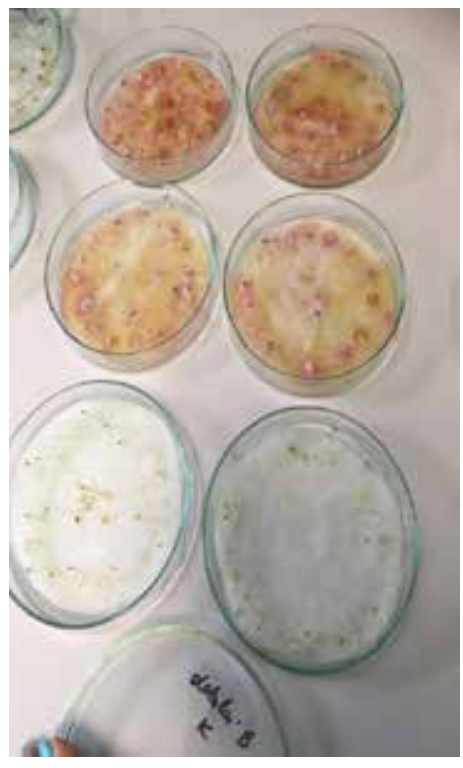

White clover

Figure 1. Symptoms on seeds inoculated with F. graminearum (4vkv4) compared with control (water) at 4 DAI. Figure shows inoculated bean, pea and white clover seeds. Each seed is presented on four (upper) inoculated and two (bottom) control plates. 
The germination of various plant seeds inoculated with $F$. graminearum $4 \mathrm{vkv} 4$

\begin{tabular}{|l|c|l|c|c|}
\hline \multirow{2}{*}{ Seeds } & \multicolumn{2}{|c|}{ Energy, \% } & Reduction, \% & Index \\
\cline { 2 - 5 } & \multicolumn{2}{|c|}{3 DAI } & 3 DAI & 6 DAI \\
\hline Bean & 36 & $\mathrm{~b}$ & 39 & 0.2 \\
\hline Lupine & 8 & $\mathrm{ab}$ & 77 & 0.0 \\
\hline Soybean & 85 & $\mathrm{c}$ & 78 & 1.3 \\
\hline Pea & 3 & $\mathrm{a}$ & 78 & 0.0 \\
\hline Lucerne & 94 & $\mathrm{cde}$ & 76 & 5.5 \\
\hline White clover & 96 & $\mathrm{e}$ & 79 & 2.8 \\
\hline Red clover & 90 & cde & 79 & 5.5 \\
\hline
\end{tabular}

Note. Values with different letters in the columns are significantly different according to Duncan's test at $\mathrm{P}<0.05$.

found out that $F$. graminearum is an important seed and seedling pathogen of maize and soybean.

The seeds were inoculated with a macroconidial suspension of $F$. graminearum to test for the probability to cause infection. The symptoms of $F$. graminearum infection showed up after 2 DAI and the germination index of bean, pea, lupine, soybean, lucerne, white and red clover seeds scored after 6 DAI (Figure 1). In an examination of inoculated seeds with $F$. graminearum, red-purple mycelium growth was detected on the seeds (infection from 21.25 up to $100 \%$ ). The results show that the percent of seed infection and seedling germination depends on the plant species (Figure 2). Broders et al. (2007) evaluated 105 isolates of $F$. graminearum and found out the moderate and high level of pathogenicity on both maize and soybean.

The seed germination energy, after inoculation of different plant seeds with $F$. graminearum, showed variation between plant species (Table 1). The germination energy in inoculated seeds varied from $2.56 \%$ in pea to $96.25 \%$ in white clover. The results showed that germination energy decreased on pea $(2.56 \%)$ and lupine $(7.79 \%)$ seeds. Very low germination energy shows high susceptibility to infection. Our results of nearly all tested seeds showed that germination reduction was observed by almost $80 \%$. This study showed that germination index varied within different plant seeds. Purahong et al. (2012) found out that germinated wheat seeds after 2 DAI and healthy seedling inoculated with $F$. graminearum decreased compared with control. Farrag \& Moharam (2012) reported that $F$. oxysporum and $F$. solani inoculated cucumber (Cucumis sativus L.) seed germination decreased compared with control.

The results of $F$. graminearum contamination on various plant seeds are provided in Figure 2. The symptoms of $F$. graminearum infection on seeds were observed on 2 and 6 DAI. The inoculated seeds with $F$. graminearum were accompanied by characteristic red-purple mycelium completely covering different plant seeds (Figure 1). The highest infection of $F$.

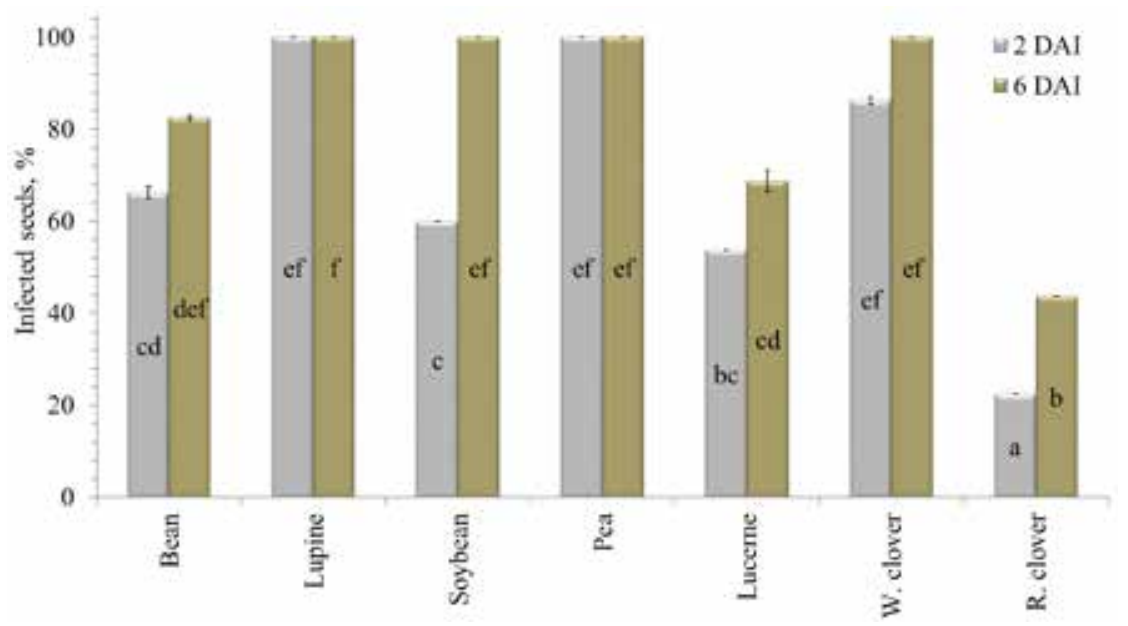

Figure 2. The infection of various seeds inoculated with $F$. graminearum isolate 4vkv4. Values with different letters in the columns are significantly different according to Duncan's test at $\mathrm{P}<0.05$. 
graminearum was obtained on pea and lupine seeds $(100 \%)$. It was established that white clover $(86 \%)$ seeds after 2 DAI were infected similarly as lupine and pea. Moderate infection after 2 DAI was on lucerne (53\%), soybean $(60 \%)$ and bean $(66 \%)$. The lowest infection was seen on red clover at $2 \mathrm{DAI}-22 \%$, as well as $6 \mathrm{DAI}-43 \%$. This study shows that after 6 DAI a similar tendency of infection was observed as after 2 DAI. The results show that the highest susceptibility to $F$. graminearum had pea and lupine seeds and the least red clover. Purahong et al. (2012) found out different aggressiveness of $F$. graminearum isolates on wheat seeds. Farrag \& Moharam (2012) reported dominance of Fusarium spp. (32\%) pathogens followed by Rhizoctonia spp. (12\%). This study demonstrated the $F$. graminearum capability to infect various plant seeds. Our data indicate that red clover is more suitable for cereal crop rotation, because of less susceptibility to $F$. graminearum. On the other hand, peas and lupines grown in cereal crop rotation could serve as an alternative host and source of inoculum, though leaving $F$. graminearum infected residues in the field. Therefore, further studies and monitoring are still required.

\section{Conclusions}

In our case, bean, pea, lupine, soybean, lucerne, white and red clover seeds showed susceptibility to $F$. graminearum. The results obtained in this study suggest that various seeds differently react to $F$. graminearum infection. As present research shows, red clover is less susceptible to $F$. graminearum. It was found that the highest susceptibility to $F$. graminearum had pea and lupine seeds. However, further studies and monitoring is still required.

\section{Acknowledgements}

This research was funded by a grant (No. SIT05/2015) from the Research Council of Lithuania through the National Research Program 'Sustainability of agro-, forest and water ecosystems'.

\section{References}

1. Ali, S., Rivera, V.V., \& Seco, G.A. (2005). First report of Fusarium graminearum causing dry rot of potato in North Dakota. Plant Disease, 89(1), 105. DOI: 10.1094/PD-89-0105B.

2. Aswathaiah, B., Gupta, D.G., Ramegowda, \& Reddy, M.V. (1993). Germination Testing. In Agarwal, P.K., (Ed.), Handbook of Seed Testing (pp. 45-92). National Seed Corporation, New Delhi.

3. Barros, G.G., Zanon, M.S.A., Chiotta, M.L., Reynoso, M.M., Scandiani, M.M., \& Chulze, S.N. (2014). Pathogenicity of phylogenetic species in the Fusarium graminearum complex on soybean seedlings in Argentina. European Journal of Plant Pathology, 138, 215-222. DOI: 10.1007/s10658-013-0332-2.

4. Borgen, A. (2005). Removal of bunt spores from wheat seed lots by brush cleaning. ICARDA Seed Info, $29,13-15$.

5. Broders, K.D., Lipps, P.E., Paul, P.A., \& Dorrance, A.E. (2007). Evaluation of Fusarium graminearum associated with corn and soybean seed and seedling disease in Ohio. Plant Disease, 91, 1155-1160. DOI: 10.1094/PDIS-91-9-1155.

6. Burlakoti, R.R., Ali, S., Secor, G.A., Neate, S.M., McMullen, M.P., \& Adhikari, T.B. (2008). Genetic Relationships Among Populations of Gibberella zeae from Barley, Wheat, Potato, and Sugar Beet in the Upper Midwest of the United States. Phytopathology, 98(9), 969-976. DOI: 10.1094/PHYTO-98-9-0969.

7. Cram, M.M., \& Fraedrich S.W. (2010). Seed Diseases and Seedborne Pathogens of North America. Tree Planters'Notes, 53(2), 35-44.

8. Demeke, T., Clear, R.M., Patrick, S.K., \& Gaba, D. (2005). Species-specific PCR-based assays for the detection of Fusarium species and a comparison with the whole seed agar plate method and trichothecene analysis. International Journal of Food Microbiology, 103, 271-284. DOI: 10.1016/j. ijfoodmicro.2004.12.026.

9. Farrag, E.S.H., \& Moharam, M.H.A. (2012). Pathogenic fungi transmitted through cucumber seeds and safely elimination by application of peppermint extract and oil. Notulae Scientia Biologicae, 4(3), 83-91. DOI: $10.15835 / \mathrm{nsb} 437969$.

10. Leslie, J.F., \& Summerell, B.A. (2006). The Fusarium laboratory manual. USA: Blackw. Publ.

11. Mourelos, C.A., Malbran, P.A., Ghiringhelli, P.D., \& Lori, G.A. (2014). Gramineous and non-gramineous weed species as alternative hosts of Fusarium graminearum, causal agent of Fusarium head blight of wheat, in Argentina. Crop Protection, 65, 100-104. DOI: 10.1016/j.cropro.2014.07.013.

12. Nirenberg, H.I. (1976). Studie on the morphological and biological differentiation in the Fusarium species (Untersuchungenüber die morphologische und biologisch Diffrenzieerum in der Fusarium Sekion Lisiola). Mitteilungen der Biologischen Bundesanstalt für Land- und Forstwirtschaft, 169, 1-117. (in German).

13. Opio, P., \& Photchanachai, S. (2016). Heat stress influences dormancy in peanut seeds (Arachis hypogea L) cv. Khon Kaen 84-8. South Western Journal of Horticulture, Biology and Environment, 7(2), $127-137$. 
14. Purahong, W., Alkadri, D., Nipoti, P., Pisi, A., Lemmens, M., \& Prodi, A. (2012). Validation of a modified Petri-dish test to quantify aggressiveness of Fusarium graminearum in durum wheat. European Journal of Plant Pathology, 132, 381-391. DOI: 10.1007/s10658-011-9883-2.

15. Purahong, W., Nipoti, P., Pisi, A., Lemmens, M., \& Prodi, A. (2014). Aggressiveness of different Fusarium graminearum chemotypes within a population from Northern-Central Italy. Mycoscience, 55, 63-69. DOI: 10.1016/j.myc.2013.05.007.

16. Raudonius, S. (2017). Application of statistics in plant and crop research: important issues. ZemdirbysteAgriculture, 104(4), 377-382. DOI: 10.13080/z-a.2017.104.048.

17. Suproniene, S., Semaskiene, R., Juodeikiene, G., Mankeviciene, A., Cizeikiene, D., Vidmantiene, D., Basinskiene, L., \& Sakalauskas, S. (2015). Seed treatment with lactic acid bacteria against seed-borne pathogens of spring wheat. Biocontrol Science and Technology, 25(2), 144-154. DOI: 10.1080/09583157.2014.964661.

18. Supronienė, S., Sakalauskas, S., Mankevičienè, A., Barčauskaitė, K., \& Jonavičienė, A. (2016). Distribution of B type trichothecene producing Fusarium species in wheat grain and relation to mycotoxins DON and NIV concentrations. Zemdirbyste-Agriculture, 103(3), 281-288. DOI: 10.13080/z-a.2016.103.036.

19. Xu, X.M., Nicholson, P., Thomsett, M.A., Simpson, D., Cooke, B.M., Doohan, F.M., Brennan, J., Monaghan, S., Moretti, A., Mule, G., Hornok, L., Beki, E., Tatnell, J., Ritieni, A., \& Edwards, S.G. (2008). Relationship between the fungal complex causing Fusarium head blight of wheat and environmental conditions. Phytopathology, 98(1), 69-78. DOI: 10.1094/PHYTO-98-1-0069.

20. Yang, F., Jacobsen, S., Jørgensen, H.J.L., Collinge, D.B., Svensson, B., \& Finnie, C. (2013). Fusarium graminearum and its interactions with cereal heads: studies in the proteomics era. Frontiers in Plant Science, 37(4), 1-8. DOI: 10.3389/fpls.2013.00037. 